\title{
EL PRO-FEMINISMO DE LAS ÉGLOGAS VII Y VIII DE JUAN DEL ENCINA: LA BELLA Y DISCRETA PASCUALA
}

\author{
María Mercedes Guirao Silvente \\ merceguisil@hotmail.com
}

\section{RESUMEN}

En las Églogas VII y VIII de Juan del Encina, asistimos a una defensa de la mujer totalmente inédita; acorde con el mayor protagonismo de ésta dentro de la corte y con la consolidación de un modelo pastoril que aúna lo tradicional y la influencia humanista. Pascuala supera, así, sus modelos literarios (la pastorela y la serranilla) y nos sorprende con su discurso libre y autónomo — capaz de evolucionar formalmente—, su contagioso optimismo y su belleza no sólo externa, sino también interior. Su amor constante y sincero la iguala a su congénere masculino y la alza como vencedora sobre la larga y vieja guerra medieval de sexos, solidarizándose con las autoras de la Querelle y mostrando una visión positiva y moderna de la mujer.

PALABRAS ClAVE: pastora; pro-feminismo; égloga; amor cortés; Juan del Encina

\section{RÉSUMÉ}

Les Églogues VII et VIII de Juan del Encina, constituent une défense des femmes absolument inédite, en relation avec la réussite des dames dans la cour et la consolidation d'un masque bucolique, qui lie la tradition avec l'influence humaniste. Pascuala dépasse ses modèles littéraires (la pastourelle et la serranilla) et surprend avec un discours libre et indépendant — capable d'évoluer-, un optimisme contagieux et une beauté non seulement externe, mais intérieure. L'amour fidèle et sincère l'égalise à son congénère masculin et lui offre un triomphe sur la longue et vieille bataille des sexes au Moyen Âge. Pascuala se fraternise avec les écrivains de la Querelle et rend une nouvelle image de la femme, beaucoup plus positive et moderne.

MoTS CLÉs: pastoure/bergère; pro-féminisme; églogue; amour courtois; Juan del Encina 
El modelo pastoril, que Juan del Encina convierte en seña de identidad literaria y que defiende a ultranza desde su sólida formación humanística —uniendo la auctoritas clásica con la recepción amena (Bustos, 2014:17)_, presenta una clara defensa de la mujer y del amor humano, en la línea de esa larga y compleja corriente pro-fémina que atraviesa todo el Cuatrocientos y que se enriquece, en estos momentos de transición, con la nueva visión sobre la mujer que trae el Humanismo. La importancia adquirida por las damas en la avanzada Italia, la expresa muy bien miser César Gonzaga en El cortesano de Baldassare de Castiglione:

[...] no puede haber corte ninguna, por grande o maravillosa que sea, que alcance valor ni lustre ni alegría sin damas, ni Cortesano que tenga gracia o sea hombre de gusto y esforzado, o haga jamás buen hecho, sino movido y levantado por la conversación y amor dellas (Crespo, 2008:303).

Pero, también en España la mujer y el amor se habían convertido, a lo largo del S. XV, en protagonistas ineludibles de la vida cortesana, en la que se habían puesto de moda las grandes fiestas y banquetes, los bailes y galanteos, y donde las vistosas escenificaciones de asuntos pastoriles y caballerescos, pretendían hacer patente cierta elevación espiritual de la nobleza; alejada ahora —en la comodidad del palacio- de los afanes guerreros de siglos anteriores. El amor por una dama infundía valor al caballero y desarrollaba sus virtudes, como refleja la literatura culta del momento. Incluso, cuando se vayan asentando las ideas humanistas, se producirá una honda preocupación por el papel social de la mujer —condenada durante tantos siglos al silencio-, en aquella sociedad en transformación (Suárez, 2008:85-128; Segura, 1997:219-245). Desde el reinado de Juan II y su primera esposa, la reina doña María —en torno a la cual se realizan importantes e influyentes tratados apologéticos: los de Rodríguez del Padrón, Diego Valera y Álvaro de Luna (Vélez, 2013:154-189)—, hasta el reinado de los Reyes Católicos, con la decidida actuación de la reina Isabel —instruida por Beatriz Galindo y poseedora de los escritos de Christine de Pizan-, en favor de la formación de sus hijas y damas; se crea un clima propicio para la instrucción de la mujer, incluso en las lenguas clásicas — las puellae doctae (Rivera, 1997:115-129)—. Asimismo, se necesita y avala una más activa participación de la mujer en la vida cultural de su tiempo, como muestran las relevantes lectoras a las que Diego de San Pedro o Juan de Flores dedican sus ficciones sentimentales; esas ingeniosas damas cortesanas que intervienen en los cancioneros castellanos del XV (Pérez Priego, 1990); o los ejemplos de participación femenina en momos y entremeses, como los que se describen en las celebraciones que tuvieron lugar en el palacio jienense del condestable don Miguel Lucas de Iranzo o en los momos de Francesc Moner y Gómez Manrique (Surtz, 1992; Pérez Priego, 2009). Tanto es así, que el maestro italiano Lucio Marineo Sículo, en su Hispanis Laudibus, se admira de las damas españolas «elocuentes y sin complejos ante los hombres, en quienes ven sus iguales» (Márquez, 2005:14).

Encina estuvo en ese bando humanista que miraba hacia el futuro, enarbolando la bandera de la mesura y la razón, frente a toda una tradición medieval misógina, que se sentía ya obsoleta y agotada. En su poema «Contra los que dicen mal de mujeres» (Pérez Priego, 1990: 
202-208), él mismo se define en el lado de los defensores, a los que loa con orgullo, frente al de los maldicientes - el del Pere Torroella ficticio y archimisógino asesinado por las damas escocesas en Grisel y Mirabella de Juan de Flores-, que no merece sino su odio y repulsión: «peor muerte que Torrellas/en placer nunca se vea/y de dios maldito sea,/el que dixere mal dellas» (vv.176-180). Pero para él, además, no sólo las damas, sino todas las mujeres, sea cual sea su condición social, son dignas de alabanza: «no ay muger, según su estado/ que no tenga ningún primor/que merezca ser loado» (vv. 163-165), y así lo demuestra también en sus piezas dramáticas de tema amoroso; desde las dos que compuso con personajes femeninos en su primera etapa salmantina: la Égloga en requesta de unos amores, y su continuación, la Égloga de Mingo, Gil y Pascuala (nuestras Églogas VII y VIII), hasta las más idealistas y paganas de su segunda época; fruto de su enriquecedor contacto con Italia: la Égloga de Cristino y Febea, la de Fileno, Zambardo y Cardonio y la de Plácida y Vitoriano.

Resulta demasiado parcial considerar las primeras piezas dramáticas de Juan del Encina — compuestas entre 1492 y 1496, bajo el mecenazgo de los duques de Alba- y su defensa del disfraz rústico-pastoril, únicamente como un rasgo que lo vincula folklóricamente a su tierra y se justifica en sus supuestos orígenes humildes y conversos; sin advertir su carácter humanista y sin atender a la modernidad que suponía el hecho de traducir a un autor clásico como Virgilio, con la misma intención que, en esos últimos años del xv, lo hacían en Italia Pulci, Scala o Lorenzo de Medici, consiguiendo un modelo bucólico hispánico antes de la llegada a las letras españolas de Boscán y Garcilaso (Bustos, 2014:19). Y, de la misma forma, debemos comprender que su defensa de la mujer, a través de su modelo pastoril, existía ya en las dos piezas señaladas de su etapa salmantina, antes de su viaje a Italia —aunque después se viera, claro está, reforzada por el Neoplatonismo-. El optimismo y la concepción lúdica de la vida que emana de las Églogas VII y VIII de Juan del Encina, donde la mujer real se percibe como un ser inteligente, aficionada a la música y la literatura, protagonista de diversiones y bailes ${ }^{1}$, y donde la hermosa e inteligente Pascuala, es capaz de resolver los conflictos de las dos obras en que aparece y de de ayudar, en fin, al triunfo del amor y la felicidad, se opone a esa visión negativa de la misma que se ofrecía frecuentemente en la literatura ascética y en la didáctica medieval, para acercarla al espíritu moderno y laico del Renacimiento.

Tanto la Égloga VII como la VIII poseen, además, muchas referencias internas al lugar de representación, poniendo casi a un mismo nivel a los espectadores y a los personajes; hecho que va a suponer que su reivindicación femenina sea muy efectiva. En la rúbrica inicial se nos dice, de este modo, que «una pastorcica llamada Pascuala, yendo cantando con su

${ }^{1} \mathrm{Si}$ en las avanzadas y bulliciosas cortes italianas que pronto conocería Encina, mujeres de exuberante belleza y brillante conversación, con grandes dotes musicales y artísticas, alternaban con la nobleza, los principales cargos municipales y la alta jerarquía eclesiástica, algunas de las cuales, como Vittoria Colonna, Casandra Fedele o Isabel de Luna, fueron realmente admiradas (Burckhardt, 1982:304-311); también en la corte castellana se había elogiado la belleza e ingenio de damas como doña Leonor Centellas, doña Marina Manuel, doña Catalina Manrique, doña Isabel Vergara, la reina Juana de Avis —esposa de Enrique IV—o la dama Vayona (Pérez Priego, 1990), y hasta la misma princesa Isabel había participado, junto con otras jóvenes castellanas en el momo que Gómez Manrique compuso para homenajear a su hermano Alfonso (Pérez Priego, 2009:150-155), contribuyendo a crear ese ambiente tan propicio para el lucimiento femenino al que nos hemos referido durante el reinado de los Reyes Católicos. 
ganado, entró en la sala adonde el duque y la duquesa estaban» y cómo posteriormente entran Mingo y luego el Escudero y se enzarzan en una disputa amorosa por la pastora, en la que se enfrentan el mundo pastoril y el cortesano, que se resuelve felizmente con la elección de ésta, que escoge sabiamente al Escudero, el cual se transforma en el pastor Gil. En la siguiente Égloga vuelven a entrar los pastores en el salón, sumándose a ellos Menga, que se admira de la rica decoración del palacio, y los cuatro acaban mudando sus ropas y haciéndose cortesanos. La representación se presenta, por tanto, de la forma más natural: los duques y nobles que los acompañan presencian una conversación entre unos personajes y unos movimientos dentro de la sala misma en la que se encuentran, en la que apenas existe separación entre realidad y ficción, ya que los pastores de la historia enciniana comparten un mismo espacio, hacen referencias explícitas a los espectadores, cambian sus ropas para vestirse como ellos y los hacen participar de su felicidad final en el villancico en exaltación del amor con el que concluye la obra, abierto plenamente al «nosotros»:

Al amor obedezcamos
con muy presta voluntad,
pues es de necessidad,
de fuerça virtud hagamos.
Al amor no resistamos,
nadie cierre a su llamar,
que no le ha de aprovechar ${ }^{2}$
(vv. 516-522).

En estos villancicos, que aparecen cerrando las obras de Encina e insistiendo en la enseñanza o idea que se puede extraer de la representación desarrollada ante los ojos de los espectadores, se produce un traslado de lo particular a lo colectivo o universal que si tiene aún bastante que ver con las sentencias o moralejas de los cuentos — despojadas, eso sí, de su gravedad-, resulta mucho más efectivo por la inmediatez que supone el teatro y la comunión que se produce entre autor, personajes y público. Ese contagio emocional a través de la música y las canciones, en las que la ficción rompe su cerco y penetra en la realidad, en los corazones de todos los receptores, nos hace participar de unos sentimientos en los que todos nos reconocemos sean cuales sean nuestros vestidos o clase social, y en los que la defensa del amor y la mujer se muestra más poderosa que la de cualquier tratado, por muy razonados argumentos que éste presente.

\section{II}

Pascuala tiene un claro precedente en los personajes femeninos de la pastorela provenzal, proyectados en Castilla en la serranilla; género eminentemente culto, que fue muy cultivado por la poesía cancioneril. Tanto la pastorela como sus posteriores derivaciones,

2 Ésta y todas las demás citas de las Églogas VII y VIII de Encina que se hacen en adelante, se toman de la edición de Miguel Ángel Pérez Priego (1991). 
muestran el fortuito encuentro campestre entre un caballero — que frecuentemente informa a los lectores en primera persona- y una pastora a la que requiere en amores, la cual puede aceptarlo o rechazarlo, según el caso. Como señala Martín de Riquer, la gracia de este tipo de composiciones estriba, principalmente, «en el diálogo, unas veces elegante, otras popular, pero que tiende a contraponer dos estamentos sociales: el aristocrático, representado por el caballero y el rústico, a cargo de la moza» (Riquer, 2001:63) y siempre, claro está, desde la óptica del estamento privilegiado. De este modo, la que es considerada como la primera de las pastorelas provenzales: «L'autrier jost'una sebissa» de Marcabrú, muestra muy bien esta oposición entre lo campesino y lo cortés y presenta a una pastora firme y desenvuelta que contesta siempre, con ingenio y desenfado, a las proposiciones del caballero, que queda al final burlado.

Tras la típica descripción de la alegría y del atuendo de la campesina —adaptado al lugar de origen de la moza en las distintas composiciones y que influiría, sin duda, en el vestuario, con los pertinentes toques realistas de rusticidad castellana, de las pastorcillas de nuestro teatro medieval y en esa actitud cantarina y risueña que veremos en pastoras como Pascuala: «cap'e gonelh'e pellissa/vest e camiza treslissa,/ sotlars e caussas de layna»33; se inicia el cortejo y esa interesada ponderación de la belleza de la pastora, que incluso Andrés el Capellán —acérrimo detractor del amor rústico-, hubiera justificado para conseguir los favores sexuales de la villana ${ }^{4}$. El caballero se atreve a insinuar, en este sentido, que sería mucho más hermosa si hiciera el amor con él, consciente de su superioridad cortés:

$$
\begin{aligned}
& \text { Toza, fi m ieu, gentil fada } \\
& \text { vos adastret, quan fos nada, } \\
& \text { d'una beutat esmerada } \\
& \text { sobre tot' autra vilayna; } \\
& \text { e seria us ben doblada, } \\
& \text { si m vezia una vegada } \\
& \text { sobira e vos sotrayna }
\end{aligned}
$$

Sin embargo, la pastora saca a colación su decencia:

mas ges per un pauc d'intratge no vuelh mon despiuzelhatge camjar per nom de putayna ${ }^{6}$.

3 «...vestía capa, saya y pelliza, y camisa de terliz, zapatos y medias de lana», (Riquer, 2001:180, vv.5-7).

4 Véase «El amor de los labriegos», en Libro del amor cortés (Rodríguez, 2006:177-178); donde, ante el amor con una villana, se aconseja aprovechar la oportunidad de un lugar idóneo y emplear, incluso, la fuerza si fuera preciso para saciar el deseo: «porque, si no va por delante el oportuno remedio de su pudor con una pequeña coacción, difícilmente podrías mitigar su resistencia aparente hasta llegar a confesar que están dispuestas a entregársete en dulces abrazos o a permitirte gozar de los placeres que de ellas esperas».

5 «Moza, dije yo, una gentil hada os dotó, cuando nacisteis, de una acrisolada hermosura, superior a la de cualquier otra campesina, y os sería aumentada el doble si me viera yo una vez encima y vos debajo [de mí]» (Riquer, 2001:182, vv.43-49).

6 «...pero no quiero, a cambio de un mezquino peaje, mudar mi doncellez por el nombre de ramera» (Riquer, 2001:183, vv. 68-70). 
Y desenmascara la falsedad de las formas corteses y la ociosidad de la nobleza, en un tono burlón, que echa mano en más de una ocasión de la picardía y del saber popular, que contrasta fuertemente con el estilo del caballero, que queda, así, desarmado y vencido:
per so n'auretz per soudada
al partir: Bada, Fol., bada!,
e la muz'a meliayna
En tal loc fai sens fraitura
on hom non guarda mezura, so diz la gens ansiayna ${ }^{7}$.

Esa tensión social entre lo rústico y lo cortesano, el halago de la belleza de la pastora como técnica persuasiva, la preocupación por la honra, el humor, la ironía o la desenvoltura de que hace gala, en ocasiones, el personaje femenino, así como la gracia, el donaire o la sensualidad de algunas pastoras provenzales influyen, sin duda, en la caracterización de personajes como Pascuala, la cual se ofrece, además, en su delicadeza e inusual finura, muy próxima a algunas bellas e idealizadas campesinas del Marqués de Santillana. Así, podríamos relacionarla con la dulce Yllana, la serrana de Loçoyuela (III), que hace proclamar al caba1lero: «Yo juro a Sant' Ana/ que non sois villana» (vv. 23-24) ${ }^{8}$, con la elegantemente vestida moza de Bedmar (VI), o con la gracia de la vaquera de la Finojosa (VII); aunque, especialmente, presenta puntos de contacto con la mozuela de Bores (IV), de la que se describe, ante el auditorio cortesano, su:

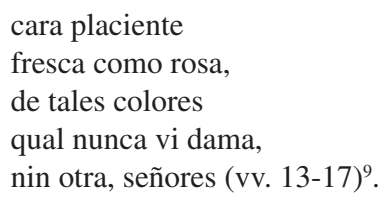

Esto provoca que el caballero la trate de «señora» y la inste a que su hermosura salga de aquel grosero ambiente:

en verdad
la vuestra beldad
saldrá desd'agora
dentr'estos alcores,
pues merece fama
de grandes loores (vv. 19-24).

Y, por supuesto, ésta — tan sensata como Pascuala—, no acepta al caballero hasta que éste no muestra su intención de hacerse pastor; sugiriéndose, en ambos casos, la feliz unión de los protagonistas, bien con el «encubrimiento cómplice de las flores del campo de Espina-

\footnotetext{
7 «tendréis por recompensa al marcharos: ¡Pásmate, bobo, pásmate! Y un plantón a mediodía [...] Dice la gente vieja. Allí el juicio hace falta donde no se guarda la mesura» (Riquer, 2001:183-184, vv. 54-56 y 81-83).

${ }^{8}$ III, [Yllana, la serrana de Loçoyuela], vv. 23-24 (Pérez Priego, 1999:111).

9 IV, [La moçuela de Bores] (Pérez Priego, 1999:113).
} 
ma» (Pérez Priego, 2010:74), bien envueltos en la soledad de la noche, tras ser oportunamente abandonados por el pastor rival, Mingo, que se va a llorar su derrota hasta que llega el alba.

La discreción de las dos pastoras y el deseo sensual que despiertan ambos personajes, que hace pensar ya en la mujer como ser de carne y hueso y no como mero símbolo de belleza, supone, sin duda, un claro avance hacia el Renacimiento. María Hernández Esteban (1984: 93) señala, en este sentido, que «lejos ya de las convenciones que sustentaron la cultura provenzal, lejos de los consejos del capellán Andrés, la pastora se valora ya como persona (al margen de un mundo donde sólo la dama casada tenía entidad social suficiente), hasta el punto de que el poeta pueda prometer o proponer a la pastora hacerse él también pastor».

La misma admiración ante la inusual belleza de una villana, la ofrece Carvajal en algunas de sus serranas de ambiente italiano, en las que describe minuciosamente el físico y el buen porte de la pastora, acercándola a los rasgos de las damas y que podemos también poner en relación con la transformación posterior de Pascuala en palaciega, que complica el argumento en ese salto de la pastorela dramatizada a la égloga que realiza Encina en las dos piezas protagonizadas por la bella pastora:

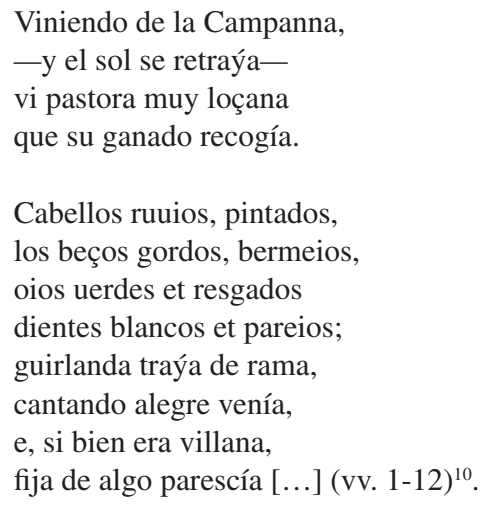

Pero, las rústicas pastoras se ofrecen, en realidad, muy distintas a las damas, pues no aparece en ellas esa fría altivez, ni la férrea salvaguarda del honor, bajando de su pedestal y adquiriendo un papel más activo y concreto, tanto en la lírica como en el teatro cortesano. Como señala M. ${ }^{a}$ Eugenia Lacarra, refiriéndose a la poesía de los Cancioneros del xv:

[...] a la villana se la alaba ocasionalmente por su castidad, se la vitupera por su lujuria, pero sobre todo se le presume una liviandad juguetona que se acepta, porque a una villana no se le exige la conducta virtuosa que se espera en una dama. La mayor flexibilidad en su representación se manifiesta en la estructura poética, de modo que el poeta ocasionalmente le concede la palabra, dando lugar al diálogo con el caballero e incluso haciéndola portavoz única de su propia voz poética (Lacarra, 1995:165-166).

Y, por supuesto, la bella Pascuala — aunque claramente idealizada y con extraordinaria capacidad para adaptarse al ambiente palaciego_-, pertenece a ese mundo rústico. La vemos,

${ }^{10}$ Véase Carvajales, «Arca Roma» (CLI), en Cancionero de Estúñiga (Salvador Miguel, 1987:622-623). 
así, al principio, hablar en sayagués o desconfiar de ese amor cortés que le ofrece el Escudero, por su educación temerosa a las frecuentes agresiones sexuales que se producían contra las campesinas, obligadas a llevar a sus ganados por tierras solitarias y agrestes ${ }^{11}$. Y sabe llevar a ese mundo cortesano en el que lúdicamente se introduce, todo el regocijo de los bailes y los cantos populares, que daban un mayor protagonismo y una mayor libertad expresiva a las mujeres, que no se avergonzaban de sus sentimientos y se rebelaban, incluso, contra los estrictos prejuicios sociales, ostentados por el pensamiento patriarcal ${ }^{12}$.

Dentro de esa compleja simbiosis y enriquecimiento mutuo que se produce entre lo popular y lo cortesano en la obra de Encina, hay que situar el original pro-feminismo de estas dos églogas; conseguido, fundamentalmente, a través de la sorpresa que produce en el espectador un personaje como Pascuala. Ella es capaz de aunar en sí misma lo pastoril y lo palaciego y de proyectar esa conciliación sobre los demás personajes, como veremos a continuación.

\section{III}

Pascuala llega con su ganado, cantando alegre y despreocupada, al palacio de los duques de Alba y allí es doblemente cortejada: primero por el pastor Mingo y después por un Escudero, dando muestra de poseer una gran serenidad y un extraordinario buen juicio. De esta forma, rechaza a Mingo, ya casado con Menga, y acepta al Escudero, siempre y cuando esté dispuesto a hacerse pastor como ella. Pero, Pascuala no sólo está dispuesta a recibir, sino que cuando el Escudero, transformado ya en el pastor Gil desde hace un año, le manifiesta, en la Égloga VIII, su deseo de volver a la vida cortesana; ella no dudará en hacer el mismo sacrificio, libremente, movida únicamente por el amor que le tiene:

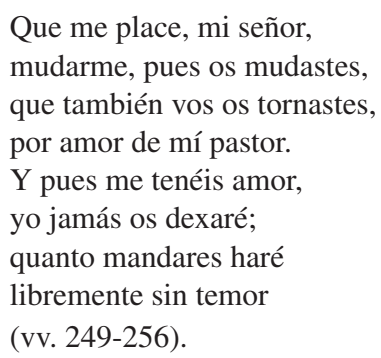

Si las elitistas normas del amor cortés ofrecidas por Andrés el Capellán, negaban que el amor entre plebeyos fuera como el de los nobles, y aconsejaba a estos últimos no enseñárselo especialmente a los labriegos para que no descuidaran sus labores campesinas:

${ }^{11}$ Las pastoras llevaban una honda y una lanza porquera para defenderse y se refugiaban en chozas y cuevas, guardando el rebaño familiar o también, a veces, rebaños ajenos, para procurarse una paga (Pastor, 2006:473).

12 Véase, a este respecto, el interesante libro de Mariana Masera (2001): «Que non dormiré sola, non». La voz femenina en la antigua lírica popular hispánica, Barcelona, Azul. 
Al labrador le basta el trabajo diario y los placeres continuos del arado y el azadón. Pero, aunque alguna y rara vez pudiera suceder que, contra su misma naturaleza, se vieran picados por el aguijón del amor, no es conveniente enseñarles la doctrina del amor. Porque mientras piensan en actividades ajenas a su condición, echaremos en falta que las tierras que suelen fructificar, gracias al trabajo de su propietario, se tornan estériles por falta de alguien que las cultive (Rodríguez, 2006:177).

Vemos que Encina desmonta ese pensamiento - todavía vigente en el S. XV en ese desprecio de la aristocracia hacia lo rústico-, en la segunda parte de la obra, con la conversión en cortesanos, no sólo de la bella Pascuala — a la que dada su natural elegancia apenas cuesta trabajo- , sino también de las figuras menos refinadas del pastor Mingo y de su esposa Menga, que no sólo mudan sus ropas, sino que están dispuestos a aprender las costumbres, bailes y juegos de la corte.

Con esta renuncia — no sin nostalgia y tal vez sólo por un tiempo (vv. 369-372) — de los pastores a la ingrata y áspera vida del campo, Encina muestra esa búsqueda de refinamiento o dignificación del mundo pastoril, que desembocará, más tarde, en la figura idealizada de Fileno; totalmente ajeno ya al ganado, a la comida o al juego que tanto preocupaban a los pastores rústicos y que, con esmerada expresión, dedica su tiempo a cantar, gravemente, sus cuitas de amor en un entorno natural embellecido, donde su disfraz pastoril es tan sólo un pretexto. En este sentido, y con una gran dosis de humor, descubrimos a Mingo, cubierto con el sayo que le ha prestado Gil y con el bonete de lado, ensayando la pose que debe adoptar el amante cortesano, siempre dolorido y contrariado por el rechazo de la amada — que Mingo dice conocer bien por el desdén de Pascuala—, y que pone en evidencia la falsedad y el amaneramiento de estos manidos tópicos amatorios, más aprendidos que sentidos:

Gil: $\quad$ Echa el bonete a un lado, assí como aqueste mío.

Mingo: ¡Pareceré jodío!

Gil: $\quad$ Calla, qu'es de requebrado.

Mingo: ¿Requebrado? ¿Cómo assí?

Dime, dime, ¿qu'es aquesso?

¿es cosa de carne y huesso o, soncas, burlas de mí?

Gil: ¡Guárdeme Dios! ¿Yo de ti?

No ayas miedo ya.

Llaman requebrado acá al que está fuera de sí.

Mingo: ¿Al que está loco?

Gil: $\quad$ No, no,

sino al que está namorado

y se muestra muy penado

por la que le enamoró.

(vv. 445-460).

Pero, si Mingo es un personaje situado en ese paso intermedio entre el pastor rudo y el refinado - esto es, combina su carácter cómico de escenas como la anterior o como la que le lleva a enumerar los muchos regalos que hará a Pascuala si lo acepta, con la galantería que 
supone cortejar a la bella pastora con una rosa o con su gallardía natural, que admira a Gil cuando lo ve con sus ropas de domingo-; Pascuala está ya plenamente idealizada. Tanto en ropas pastoriles como en ropas cortesanas, la pastora sorprende con su gracia y hermosura — recordemos que, si en la primera parte, el Escudero la piropea diciéndole «Tienes más gala que dos/ de las de mayor beldat» (vv. 53-54); Menga, al verla vestida de cortesana, suelta ese «iDome a Dios que ya semeja/ doñata de las de villa» (vv. 259-260), asombrándose de que una muchacha «...que nunca fue criada/ sino en terruño grosero» (vv. 271-272) resulte, de repente, tan distinguida- Esto es, sus dones quedan por encima de su pertenencia a una clase social u otra. Lo que se valora de ella es su interior.

Todos los calificativos que Pascuala recibe de los otros tres personajes son elogiosos. Así, si Mingo la llama «bella», «lozana», «garrida», «hermosa», el Escudero destaca su «galanía», que está muy por encima de la «grossería» del pastor y es tratada cariñosamente por éste con los diminutivos de «pastorcica» o «carilla» y hasta con el apelativo de «bendita zagala», cuando ésta decide escuchar su plática cortesana, desoyendo las recomendaciones de Mingo. Y también, en la segunda parte, recibe la admiración de Menga que, lejos de considerarla una rival, la tiene como maestra; pues ella ya ha estado en el palacio ducal y sabe cómo hay que comportarse en tan exquisitas circunstancias o los pasos que hay que dar para mudar su aspecto, cuando, a petición de Mingo, decide hacerse ella también cortesana. Los diminutivos de «Pascualilla» $\mathrm{o}$ «Pascualeja» son reflejo del cariño y la complicidad que Menga siente por la protagonista.

Pascuala, por tanto, no sólo destaca por su belleza, exaltada como extraordinaria tanto por el pastor como por el Escudero; sino, especialmente, por su honradez, su serenidad, su gentileza y su excepcional inteligencia, que la convierten, además, en un personaje fuertemente individualizado. La dulzura de su carácter y su prudencia están en paridad con su hermosura.

Así, no coquetea con Mingo, rechazándolo, desde el principio, por ser él casado y, aunque de forma cortés le agradece esa rosa de «chapados olores», se muestra más esquiva, huyendo del contacto físico con él, cuando éste se acerca para pedirle un anillo o una pulsera en prenda de su amor: «iTirte, tirte allá, Minguillo,/ no te quellotres de vero!» (vv. 41-42). Y tampoco acepta a la primera al Escudero, no creyendo en sus piropos cortesanos sobre la belleza ni en las riquezas y finuras que dice estar dispuesto a darle. Conocedora de la fama de burladores que tienen los cortesanos, lo rechaza — también como a Mingo— dos veces, antes de que se produzca el violento enfrentamiento dialéctico entre los dos rivales.

En esta suspicacia que despierta en ella el galanteo del Escudero, reside el eco de las enseñanzas de la «Querelle des femmes», con ese aviso a las mujeres sobre los engaños de los hombres que realizara Christine de Pizan en La cité des dames:

[...] Ces auteurs ne s'adressent pas aux femmes pour les conseiller de se méfier des pièges que leur tendent les hommes. Pourtant, il n'est que trop certain que les hommes trompent fréquemment les femmes par leur ruse et leur duplicité. Et il ne fait aucun doute que les femmes, elles aussi, font partie du peuple de Dieu, qu'elles sont des créatures humaines au même titre que les hommes, et qu'elles ne sont point d'une autre race ou d'une espèce différente que l'on pourrait exclure de l'instruction morale. Il fut en conclure que s'ils s'agissaient pour le bien commun, c'està-dire à la faveur des deux parties concernées, ils se seraient également adressés aux femmes pour 
les mettre en garde contre les pièges que leur tendent les hommes, comme ils l'ont fait à propos des femmes pour les hommes. (Moreau et Hicks, 2000:211-212).

De estos ardides y trampas que usan los hombres en el amor - y que contradicen los numerosos ataques que la literatura misógina lanzaba contra las mujeres: «Cómo la muger es cara con dos fazes», «Cómo la muger miente jurando e perjurando» (Arcipreste de Talavera, caps.VI y X)—; nos dan cuenta muchos personajes literarios femeninos del Cuatrocientos, que protestan contra ellos: Brazaida y Gradisa en las ficciones de Juan de Flores, Ella en las Coplas de Puertocarrero ${ }^{13}$... Incluso el poeta Pedro de Cartagena, que tanta influencia tenía en los juegos poéticos de corte, se alza en defensor de las damas, poniéndolas en guardia contra la retórica cortés de los de su propio sexo:

Con jurar falso os aplazen;
pues la tal seguridad
yo’s pido c'os aborrezca,
qu'en los ombres qu'esto hazen
no ay secreto ni verdad
ni cosa que les parezca.
Fingen los desesperados,
dizen lo que olvidan luego;
éstos son los bien librados,
que pensáys que van quemados
y ellos van libres del huego...
...Viene el tal enamorado
antes que le carguéys culpa
Y jura que n'os ha errado
pues ¿queréys ver el culpado
quien sin culpa se desculpa?
(Rodado, 2000:119-121).

Sin embargo, la reivindicación de la autora francesa va muchísimo más allá. Lo que más le preocupa no son los engaños con que los hombres ofenden a las mujeres, pues también éstas últimas utilizan ardides, en ocasiones, sino que en los libros, no se trate por igual a unos y otros y se hayan visto más graves las trampas y falsedades de las mujeres, achacando esto a una peor consideración del sexo femenino, como si fuera «una especie diferente», «excluido de una educación moral». Aquí es precisamente donde hay que situar la clara actitud pro-fémina de Encina. No es que Pascuala tenga suerte porque el Escudero no la engaña, es que sabe, por su discreción y sinceridad amorosa, ganarse el amor de éste. Y, de la misma forma, él, convertido en pastor, le muestra también su total e idéntica corres-

${ }^{13}$ Gradisa, por ejemplo, cuya obra predilecta es Fiammetta de Boccaccio, a la que subordina su propia relación con Grimalte, pues todas sus decisiones amorosas dependen de esa experiencia suya como lectora; opina lo siguiente sobre la maldad de Pánfilo: «...pues más ligeramente las mujeres se engañan, en especial amando, que no los hombres, donde no ay amor» (Parrilla, 2008:203). La protagonista de las Coplas de Puertocarreno, en cambio, no en actitud de víctima, sino de clara vencedora, hace ver al caballero que no cree en su sufrimiento: «a quitar ociosidad os entrastes /pues pasatiempo buscastes, /no fijáis necesidad, /que es tocar en liviandad» (vv. 626-630, en Pérez Priego, 2009:258-259). 
pondencia. Encina rechaza ese enfrentamiento y rivalidad de sexos - que como advertíamos al principio, quedaba ya muy desfasado-, y muestra la necesidad de que se considere por igual a hombres y a mujeres. Bien nos recuerda esa reciprocidad amorosa entre Pascuala y el Escudero, superadora de cualquier diferencia social y sexual, algunos de los más bellos versos de la lírica popular:

\author{
[...] En la fuente de agua clara \\ con sus manos lavan la cara. \\ Él a ella y ella a él, \\ lavan la niña y el doncel [...] (Frenk, 1990:80).
}

No es extraño, en este sentido, que la protagonista femenina huya de la protección que le ofrece Mingo, - que la presenta como doncella desvalida ante el asedio de la lascivia cortesana-, y decide valientemente, y desde su libertad, escuchar antes de marcharse las razones del Escudero, confiando únicamente en su buen juicio a la hora de decidir con quién se quedará. En su elección, no la mueven ni todos los presentes que le promete Mingo, desde su mundo pastoril, ni todas las riquezas que la esperarían en la corte. Muy al contrario, es ella quien al ver el sacrificio que el escudero hace al transformarse en pastor por su amor, le da, desinteresadamente, sus humildes pertenencias, y con ellas, su cariño sincero y sin engaños: «Mi çurrón y mi cayado/ tomad luego por estrena» (vv. 189-190).

En la Égloga de Mingo, Gil y Pascuala, la vemos entrar en la sala con la misma alegría que ya lo hiciera en la Égloga representada en requesta a unos amores, tan feliz en su oficio de pastora como la primera vez. Aunque ahora, transcurrido ya un año, viene acompañada por Menga, cuya simpleza — que nos ofrece un ejemplo de pastora rústica, que se asombra al llegar al palacio de los duques: «dome a Dios que esta cabaña qu'es bien chapada y bien lluenga» (vv. 176-177); y siempre va tras la protagonista: «mas primero tú, Pascuala,/ que sabes mejor la sala» (vv. 171-172) — hace resaltar, aún más, la finura e inteligencia de Pascuala.

Ambas son requeridas por sus parejas cuando éstos ya han rendido pleitesía a los duques y cumplido la misión que les llevara allí y se deciden a bailar y cantar para festejar el amor que se tienen, siendo el papel de la mujer imprescindible en estas situaciones de regocijo colectivo. El villancico que entonan, «iGasagémonos de huzia/ qu'el pesar/ viénese sin le buscar!», a mitad de la obra, tiene, además, una clara función dramática: su invitación a dejar las penas y a disfrutar de la vida pretende alejar el resentimiento del alma de Mingo, aún dolido como un niño por su derrota amorosa, y que acaba de decir a Gil que no quiere seguir componiendo música. Por otro lado, su exaltación del placer y esa fusión entre pastores y cortesanos-espectadores al son de la música, que rompe —como hemos dicho- el límite realidad-ficción, evoca en Gil la nostalgia de la vida cómoda y ociosa de la corte, a la que dice, acto seguido, querer tornar y que abre, propiamente, el conflicto que da lugar al desarrollo de la acción dramática.

Por otro lado, Pascuala se deja pronto seducir por los usos de la corte y evoluciona lingüísticamente. Así, en esta continuación aparece aún más estilizada, como si durante ese año que ha pasado con Gil hubiera aprendido de su lenguaje refinado y de sus costumbres palaciegas y, por estar en consonancia con él, la vemos adaptarse a la nueva situación con gran 
naturalidad, como si hubiese nacido cortesana y no pastora. Así, de forma paralela a la actuación de Gil con Mingo, también ella sirve de orientadora a Menga en esa nueva vida cortesana, que la rústica pastora acepta, al principio, sólo a regañadientes: «Catá que yo no sabré/ ser para ser del palacio» (vv. 377-378) y únicamente por seguir el capricho de su marido:

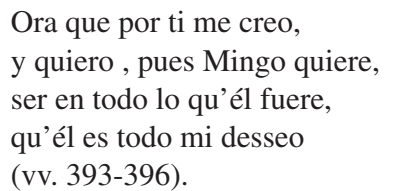

Si en la primera parte, la frescura popular del lenguaje de Pascuala, la lleva a utilizar vulgarismos y expresiones propias de su condición pastoril —recordemos, por ejemplo, la deformación vulgar «trónicas» por «retóricas» (v. 61) o la utilización de todo un léxico relacionado con el mundo campesino en que vive: «quellotres», «caramillo», «hondijo», «aballas», «cayado», «hurria», «çurrón»—; en palacio se desenvuelve como si fuera de allí, mostrando a Menga cómo debe vestirse y arreglarse y contestando a las violentas salidas humorísticas de la ruda pastora — que, como Mingo, también se resiste a cambiar sus ropas-, con gran gentileza y serenidad:

$\begin{array}{ll}\text { Menga: } & \text { ¿Qué me mude como culebra } \\ & \text { los mis cueros? ¡Tirte a huera! } \\ \text { Pascuala: } & \text { No pienses tú, compañera, } \\ & \text { que son estas curas crudas, } \\ & \text { no son sino blandas mudas } \\ & \text { y una cosa muy ligera } \\ & \text { (vv. 387-392). }\end{array}$

La transformación de la rústica pastora en cortesana es, por tanto, obra de Pascuala. Ésta exhibirá al final de la pieza a Menga, con orgullo, ante los protagonistas masculinos; los cuales, asombrados por tan enorme cambio, la piropean también a ella por primera vez llamándola «gentil» (v. 467) y observando que «no es ya esposa de pastor» (v. 468). Así, la hasta ahora simple y vulgar Menga, que había estado siempre a la sombra de Pascuala, tiene, gracias a ésta, su pequeño momento de gloria. Con todo, se trata de un cambio que apunta especialmente al físico, a la apariencia externa, arreglada de forma artificial por la destreza de Pascuala: «el rostro te curaré... te pelaré la ceja» (vv. 381 y 383); frente al cambio de la protagonista, cuya hermosura, inteligencia y gentileza — como ha demostrado a lo largo de las dos églogas - le son naturales y da igual que vista unas ropas u otras.

De todas formas, queda claro que sobre la voluntad de los propios personajes actúa siempre una fuerza superior; el infinito y caprichoso poder de Amor, a cuyos designios nadie puede escapar, según el tópico del «Omnia vincit Amor»; tan grato tanto a la poesía cancioneril como a la exaltación amorosa propia del Renacimiento, y que hace que los personajes mismos se asombren de ese extraordinario cambio que experimentan. Pues, aunque lo han elegido conscientemente y de buen grado, su decisión se muestra totalmente contraria a lo que antes defendían, produciéndose al final de la Égloga de Mingo, Gil y Pascuala esa reconciliación entre el mundo rústico y el palaciego que tan violentamente se habían enfrentado 
en el debate entre Mingo y el Escudero de la primera parte, alentado entonces por la pugna varonil en torno a la bella pastora:

$\begin{array}{ll}\text { Pascuala: } & \text { ¡Mira qué causa el amor! } \\ & \text { Que quien a mí me dixera } \\ & \text { que habría de ser de villa, } \\ & \text { como por gran maravilla, } \\ \text { Menga: } & \text { yo creer no lo pudiera. } \\ & \text { Yo no sabes qué tal era } \\ \text { antes que a Mingo quisiesse, } \\ \text { que aunque la vida me fuesse, } \\ \text { a la villa no viniera. } \\ \text { Espantáisos de Amor } \\ \text { que al palacio os convertió: } \\ \text { ¡ved quién dixera que yo } \\ \text { avía de ser pastor! } \\ \text { de todos es vencedor, } \\ \text { él pone y quita esperanza, } \\ \text { al que quiere da privanza } \\ \text { y al que quiere, disfavor. } \\ \text { Ningún galán namorado } \\ \text { no tenga quexa de mí, } \\ \text { que en pastor me convertí } \\ \text { porque fue de amor forçado. } \\ \text { Donde Amor pone cuidado } \\ \text { luego huye la razón } \\ \text { y muda la condición } \\ \text { con su fuerça y aun de grado } \\ \text { (vv. } 472-496 \text { ). }\end{array}$

Los cuatro personajes (y también el público), se ven contagiados, en fin, de ese optimismo en torno al amor y la amistad que inunda la sala al final de la pieza, que ha sido capaz de vencer los conflictos y dificultades planteadas. Y tanto la figura refinada y dulce de Pascuala como la más simple de Menga, que venían oponiéndose en escena, quedan igualadas al final, disueltas en ese claro y refrescante manantial de alegría democratizadora que trae consigo el amor verdadero; ese amor ennoblecedor del que habla el villancico final, capaz de afectar a todos los seres humanos por igual:

\footnotetext{
Amor muda los estados, las vidas y condiciones; conforma los coraçones de los bien enamorados.

El qu'es Amor verdadero despierta al enamorado haze al medroso esforçado y muy polido al grossero (vv. 530-33 y 543-45).
} 


\section{IV}

Tras las dos miradas que hemos ofrecido sobre el personaje de Pascuala - la externa y la interna-; esto es, sobre su prototípica y refinada belleza, en relación con sus modelos literarios (la pastorela y la serranilla) y sobre su inteligente y natural discreción, más cercana a esos presupuestos humanistas, que se replanteaban el rol social de la mujer en aquellos momentos de profundos cambios socioculturales y donde — aunque desfasados-, se dejaban sentir aún los ecos del largo debate sobre la condición femenina que atraviesa todo el Medievo; podemos afirmar que este personaje logra un pro-feminismo que sorprende por su clara y decidida novedad.

Pascuala tiene en el teatro la oportunidad de hablar, de intervenir en los juegos del amor con expresión propia y autónoma; bebida, por su gracia y frescura, en la voz femenina de la lírica popular. Tratándose, además, de un discurso que evoluciona formalmente, para adaptarse a ese ambiente cortesano que la seduce y que empieza a comprender de la mano de su amado Gil. Bajará de ese pedestal de hermosura, a expensas del rescate del caballero, que es siempre quien lucha y se sacrifica por la amada y transformará esa uni-direccionalidad en la bi-direccionalidad de un diálogo, donde personaje masculino y femenino entran en un juego dialéctico que evidencia una relación más cercana y real entre los dos sexos; reflejo de esa mayor participación de la mujer en la vida cultural de la corte que se producía a fines de la Edad Media y que testimoniábamos en personajes reales, como la misma Isabel la Católica y su círculo de mujeres ilustradas.

Pascuala escapa de todo patrón literario y nos ofrece una espontánea humanización, a la que la literatura cortesana del Cuatrocientos no estaba acostumbrada. Nos desvela, así, su belleza no sólo exterior, sino también interior, que, entre otros muchos aspectos a los que nos hemos referido, se demuestra en su sana complicidad con Menga; esa pastora, más oscura y convencional, que teme - a diferencia de Pascuala—, a lo desconocido y que, gracias a ella y a los afeites que le propone, consigue, al final, ese pequeño momento de glamour. Y también Menga, en su cariñosa simpleza, sabe agradecer los gestos que Pascuala tiene con ella, con esos diminutivos que le dirige o con los piropos a su físico, pero también a su porte distinguido y a su mismo ingenio. En ello descubrimos, sin duda, esa solidaridad entre mujeres de la que nos da cuenta la escritura femenina de la época y no sólo la de Christine de Pizan, sino la de autoras españolas, como Teresa de Cartagena, Isabel de Villena o Florencia Pinar, conscientes de su inferioridad en el acceso a la palabra y, por ende, de su marginación social y cultural. Por otro lado, la presencia de un mundo femenino propio y cerrado al masculino, donde las mujeres, en alegre camaradería, se desenvuelven con soltura y hablan de cosméticos o de ropas favorecedoras (Martínez Crespo, 1993:207-210) muestra lo obsoleto que queda el discurso de las remedia amoris contra el arreglo femenino, sobreponiendo un concepto positivo del mismo, que El Cortesano de Castiglione recomendará en las damas: «...Deba esta Dama tener buen juicio en escoger la manera del vestido que la haga parecer mejor, y la que le sea más conforme a lo que ella entienda de hacer aquel día...» (Crespo, 2008:313), y que anhelarán las mujeres del pueblo llano. Recordemos, en este sentido, la envidia de Areúsa hacia una dama como Melibea (IX, $2^{\mathrm{a}}$ ), por no poder ella hacer por su físico todo lo que quisiera: «las riquezas las hacen a éstas hermosas y alabadas, que no las gracias de su cuerpo» (Russell, 2007:422). 
Pero, sobre todo, destacaremos que Pascuala es capaz de igualarse a su congénere masculino en el amor; ambos se sacrifican al cambiar de estado y ambos reciben como recompensa la felicidad de un amor correspondido. Actúa siempre movida por el sentido común y no duda en mostrar unos sentimientos auténticos, sin esos prejuicios que el sistema patriarcal imponía injustamente a las mujeres. Su entrega incondicional está por encima de esa diferencia social, que resulta tan artificial al enfrentarse con la fuerza de su amor auténtico. Y, por supuesto, con su comportamiento a lo largo de las dos piezas, demuestra a todos esos hombres autores de libros — contra los que clama Christine de Pizan en La cité des dames-, que la mujer sí tiene «educación moral» y que puede comportarse con la misma dignidad que el hombre, siendo constante y sincera en el amor.

Para terminar, recordaremos esa acertada apreciación que sobre estas dos piezas dramáticas de Encina — no valoradas aún suficientemente y oscurecidas por la fuerza de las piezas amorosas de su segunda época- hiciera Stanislav Zimic:

[...] es también sugestivo que ya en las dos últimas Églogas del Cancionero de 1496 se formule una visión exaltadora del amor, basado en una profunda y recíproca admiración, en la absoluta, mutua confianza, en la disposición incondicional a cualquier sacrificio necesario y, en suma, en la perfecta armonía de las voluntades. [...] la delicada y sutil matización de los caracteres, la muy ágil articulación de los episodios, el encanto poético, musical de los bailes y canciones constituyen, conjuntamente, uno de los logros más bellos y deleitosos de la producción dramática enciniana (Zimic, 1986:56-57).

A lo que nosotros podemos añadir que todo ello es posible, en gran medida, a la fuerza y decisión dramática de su protagonista femenina, la bella y discreta Pascuala; que guía las acciones y actitudes de los demás personajes y propicia, con su gracia e ingenio, que la comunión entre pastores y público, tan necesaria en un arte colectivo como el teatro, se lleve a cabo y que la reivindicación de la mujer, dentro de ese divertido juego entre la realidad y la ficción de estas representaciones, resulte socialmente eficaz.

\section{REFERENCIAS BIBLIOGRÁFICAS}

BurCKHARDT, JACOB (1982): La cultura del Renacimiento en Italia, 4. a reimpresión 2012, Madrid, Biblioteca Edaf-146.

Bustos TÁuler, Álvaro (2014): «'Sonriéndome estoy’: Juan del Encina y sus pastores ante la tradición cómica y dramática», en Díez Borque, José M. ${ }^{a}$ (dir.), ¿Hacia el gracioso?: comicidad en el teatro español del siglo XVI, Madrid, Visor Libros.

Crespo Pérez, Ángel, Ed., (2008): Baldassare de Castiglione, El cortesano, Madrid, Alianza Editorial (L5721).

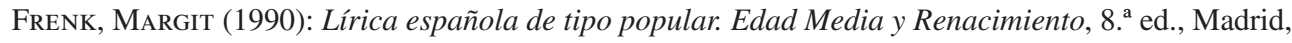
Cátedra (Letras Hispánicas, 60).

Hernández Esteban, María (1984): «Pastorela, ballata, serrana», DICENDA. Cuadernos de filología hispánica, 3, pp.73-96. http://revistas.ucm.es/index.php/DICE/article/view/DICE8484110073A/13416.

LACARra, M. ${ }^{a}$ Eugenia (1995): «Representaciones femeninas en la poesía cortesana y en la narrativa sentimental del siglo XV», en Zavala, Iris M. (coord.), Breve historia feminista de la literatura española (en lengua castellana), II. La mujer en la literatura española, Barcelona, Anthropos, pp. 159-175. 
MASera, Mariana (2001): «Que non dormiré sola, non». La voz femenina en la antigua lírica popular hispánica, Barcelona, Azul.

Márquez de la Plata y Ferrándiz, Vicenta María (2005): Mujeres renacentistas en la corte de Isabel la Católica, Madrid, Castalia.

Martínez Crespo, Alicia (1993): «La belleza y el uso de afeites en la mujer del siglo XV», DICENDA. Cuadernos de filología hispánica, 11, pp. 197-221. http://revistas.ucm.es/index.php/DICE/article/ view/DICE9393110197A/13217

Moreau, Thérese et Éric Hicks, Eds., (2000): Christine de Pizan, La cité des dames, Paris, Stock/ Moyen Âge.

Parrilla, Carmen, Ed., (2008): Juan de Flores, Grimalte y Gradisa, Alcalá de Henares, Centro de Estudios Cervantinos.

PASTOR, Reyna (2006): «Mujeres populares. Realidades y representaciones», en Morant, Isabel (dir.), Historia de las mujeres en España y América latina, I. De la prehistoria a la Edad Media, 2. ${ }^{\text {e ed., }}$ Madrid, Cátedra, pp. 445-477.

Pérez Priego, Miguel Ángel (1990): Poesía femenina en los cancioneros, Madrid, Castalia/Instituto de la Mujer (Biblioteca de escritoras).

- Ed., (1991): Juan del Encina, Teatro completo, Madrid, Cátedra (Letras Hispánicas, 339).

- Ed., (1999): Marqués de Santillana, Poesía lírica, Madrid, Cátedra (Letras Hispánicas, 475).

- Ed., (2009): Teatro medieval, Madrid, Cátedra (Letras Hispánicas, 646).

- (2010): Literatura española medieval (El siglo XV), Madrid, Ed. Universitaria Ramón Areces.

RiQuer, MARTín DE (200I): Los trovadores. Historia literaria y textos, I, 4. ${ }^{a}$ ed., Barcelona, Ariel.

Rivera Garretas, María-Milagros (1997): «Las prosistas del humanismo y del Renacimiento (14001550)», en Zavala, Iris M. (coord.), Breve historia feminista de la literatura española (en lengua castellana), IV. La literatura escrita por mujer (de la Edad Media al S.XVIII), Barcelona, Anthropos, pp. 83-129.

Rodado Ruiz, Ana, Ed., (2000): Poesía. Pedro de Cartagena, Cuenca, Ediciones de la Universidad de Castilla- La Mancha.

Rodríguez Santidrián, Pedro, Ed., (2006): Andrés el Capellán, Libro del amor cortés, Madrid, Alianza Editorial (L5085).

Russell, Peter E., Ed., (2007): Fernando de Rojas, La Celestina. Comedia o Tragicomedia de Calisto y Melibea, 3. ${ }^{a}$ ed., Madrid, Clásicos Castalia.

Salvador Miguel, Nicasio, Ed., (1997): Cancionero de Estúñiga, Madrid, Alhambra.

Segura Graíño, Cristina (1997): «La transición del Medievo a la modernidad», en Garrido, Elisa (Ed.,), Historia de las mujeres en España, Madrid, Síntesis, pp. 219-245.

SuÁrez Miramón, ANa (2008): «Entre el silencio y la palabra: escritura femenina en el Renacimiento», en Pérez Priego, Miguel Ángel (coord.), Melchor Cano y Luisa Sigea. Dos figuras del Renacimiento español, Tarancón, Ayuntamiento de Tarancón-UNED (Seminario de estudios conquenses), pp. 83-128.

Surtz, Ronald E., Ed., (1992): Teatro castellano de la Edad Media, Madrid, Clásicos Taurus-13.

VÉlez SAInz, Julio (2013): «De amor, de honor e de donas». Mujer e ideales corteses en la Castilla de Juan II (1406-1454), Madrid, Editorial Complutense.

Zimic, Stanislav, Ed., (1986): Juan del Encina, Teatro y poesía, Madrid, Taurus-169. 
